\title{
Melatonin inhibits proliferation and viability and promotes apoptosis in colorectal cancer cells via upregulation of the microRNA-34a/449a cluster
}

\author{
GUANGYU JI ${ }^{1}$, WENJUAN ZHOU ${ }^{1}$, XIAN LI $^{1,2}$, JINGYI DU $^{1},{\text { XINYUE } \text { LI }^{1}}^{\text {and HONGBO HAO }}{ }^{3}$ \\ ${ }^{1}$ Key Laboratory for Experimental Teratology of Ministry of Education, Shandong Key Laboratory of Mental Disorders, \\ Department of Anatomy and Histoembryology, School of Basic Medical Sciences, Cheeloo College of Medicine, \\ Shandong University; ${ }^{2}$ Department of Foot and Ankle Surgery, The Second Hospital, Cheeloo College of Medicine, \\ Shandong University, Jinan, Shandong 250012; ${ }^{3}$ Department of General Surgery, \\ Shandong Provincial Hospital Affiliated to Shandong University, Jinan, Shandong 250021, P.R. China
}

Received May 9, 2020; Accepted October 20, 2020

DOI: $10.3892 / \mathrm{mmr} .2021 .11826$

\begin{abstract}
Colorectal cancer (CRC) has a significant burden on healthcare systems worldwide, and is associated with high morbidity and mortality rates in patients. In 2020, the estimated new cases of colon cancer in the United States are 78,300 in men and 69,650 in women. Thus, developing effective and novel alternative agents and adjuvants with reduced side effects is important to reduce the lethality of the disease and improve the quality of life of patients. Melatonin, a pineal hormone that possesses numerous physiological functions, including anti-inflammatory and antitumor activities, can be found in various tissues, including the gastrointestinal tract. Melatonin exerts anticarcinogenic effects via various mechanisms; however, the identified underlying molecular mechanisms do not explain the full breadth of anti-CRC effects mediated by melatonin. MicroRNAs (miRs) serve critical roles in tumorigenesis, however, whether melatonin can inhibit $\mathrm{CRC}$ by regulating miRs is not completely understood. In the present study, the roles and mechanism underlying melatonin in CRC were investigated. The proliferation of human CRC cells was tested by CCK8, EDU and colony formation assay. The apoptosis of cancer cells was detected by flow cytometry and western blotting. A xenograft mouse model was constructed and the proliferation and apoptosis of tumor tissue was detected by Ki-67 and TUNEL staining assay respectively. Reverse transcription-quantitative PCR and western blotting were performed to measure the regulation of miRs on mRNA, and the dual-luciferase report analysis experiment was used
\end{abstract}

Correspondence to: Professor Hongbo Hao, Department of General Surgery, Shandong Provincial Hospital Affiliated to Shandong University, 324 Jingwu Road, Jinan, Shandong 250021, P.R. China E-mail: hongbohao1001@163.com

Key words: melatonin, colorectal cancer, microRNA-34a/449a cluster, proliferation, apoptosis to verify the direct target genes of miRs. Compared with the control group, melatonin inhibited viability and proliferation, and induced apoptosis in CRC cells. Additionally, the effect of melatonin in a xenograft mouse model was assessed. Compared with the control group, melatonin significantly enhanced the expression levels of the miR-34a/449a cluster, reduced CRC cell proliferation and viability, and increased CRC cell apoptosis. Finally, the dual-luciferase reporter assay indicated that Bcl-2 and Notch1 were the target mRNAs of the miR-34a/449a cluster. To the best of our knowledge, the present study was the first to suggest that melatonin inhibited proliferation and viability, and promoted apoptosis in CRC cells via upregulating the expression of the miR-34a/449a cluster in vitro and in vivo. Therefore, melatonin may serve as a potential therapeutic for CRC.

\section{Introduction}

Colorectal cancer (CRC) is one of the most common types of malignant cancer of the digestive system worldwide, displaying high incidence and mortality rates (1,2). In 2020, the estimated new cases of colon cancer in the United States are 78,300 in men, and 69,650 in women, accounting for 8-9\% of all cancer cases (2). Currently, the standard therapeutic strategy used for CRC is surgical resection combined with radio-chemotherapy (3); however, recurrence following curative resection is a major issue (4). Additionally, treating CRC using chemotherapy may result in cytotoxic side effects and the development of resistance, highlighting the importance of the development of more effective and novel therapeutics and adjuvants $(5,6)$. Melatonin has been highlighted as a potential alternative therapeutic due to its low toxicity and high efficacy (7).

Melatonin (N-acetyl-5-methoxytryptamine) is a pineal hormone and its release is regulated by the light/dark cycle (8). In addition to its presence in the pineal gland, melatonin also exists in other tissues, such as the liver and gastrointestinal tract $(9,10)$. Melatonin regulates numerous physiological functions, including the circadian rhythm (11), antioxidative 
protection, and anti-inflammatory $(12,13)$ and antioncogenic activities $(14,15)$. In particular, melatonin displays a range of protective effects in the gastrointestinal tract, such as enhancing the immune functions of the gut (10) and altering the composition of the intestinal microbiota $(16,17)$. Moreover, melatonin may inhibit the development and progression of gastrointestinal cancer $(18,19)$. Previous studies have demonstrated that the expression levels of melatonin in the blood of patients with CRC are disordered, which may increase the incidence of CRC (20,21). Riabykh et al (22), Farriol et al (23) and Anisimov et al (24) reported that melatonin inhibited CRC cell proliferation via decreasing DNA synthesis and promoting cell differentiation. Hong et al (25) and León et al (26) reported that melatonin induced CRC cell apoptosis by altering cell cycle progression or reducing endothelin-1 expression. Although the mechanisms underlying melatonin-mediated inhibition of proliferation and induction of apoptosis in CRC cells have been studied, the identified mechanisms cannot fully explain the breadth of antitumor effects mediated by melatonin.

Increasing evidence has demonstrated that dysregulated expression of microRNAs (miRs/miRNAs) serves critical roles in the tumorigenesis of several types of cancer (27-31). Highly expressed miR-21 and miR-155 are associated with the metastasis and poor prognosis of colon cancer (30). miR-195 functions as a tumor suppressor in colon cancer (31) . miRNAs are single-stranded non-coding RNAs 18-24 nucleotides in length (32). miRNAs affect the stability of mRNA transcription and protein translation by targeting the 3'-untranslated region (UTR) of their target mRNAs (33-35). miRNAs may serve as oncogenes or tumor suppressors, and are involved in cancer development and numerous cellular processes (36-38). miRNAs frequently reside in clusters that include $>2-3$ miRNA genes with pairwise chromosomal distances of $\leq 3,000$ nucleotides in the genome (39). Members of miRNA clusters are generally similar in sequence and are transcribed in the same direction (40). miRNAs are highly conserved and usually function synergistically $(41,42)$.

Notably, miRNAs are involved in melatonin-induced inhibition of proliferation in gastric cancer, prostate cancer and gliomas (43-45); however, the functions and mechanisms underlying melatonin and miRNAs that are involved in CRC are not completely understood. The present study examined the effects of melatonin on cell proliferation and apoptosis in CRC in vitro and also investigated whether melatonin could inhibit the tumor growth of tumor-bearing nude mice in vivo. In addition, it investigated the relationship between miRNAs and melatonin in CRC.

\section{Materials and methods}

Cell culture. HCT116, LoVo, SW480, SW620, HT-29 and DLD-1 human CRC cell lines were purchased from ATCC. All cells were cultured in DMEM (HyClone; Cytiva) supplemented with 10\% FBS (Shanghai ExCell Biology, Inc.) and 1\% penicillin-streptomycin-amphotericin B [MACGENE (Beijing) Biotechnology Ltd.] at $37^{\circ} \mathrm{C}$ in a humidified incubator with $5 \% \mathrm{CO}_{2}$.

Cell viability assay. Cell viability was assessed by performing MTT (Sigma-Aldrich; Merck KGaA) and Cell Counting
Kit-8 (CCK-8; APExBIO Technology LLC) assays. Briefly, HCT116, LoVo, SW480, SW620, HT-29 and DLD-1 human CRC cell lines were seeded $\left(8 \times 10^{3}\right.$ cells/well $)$ into 96-well plates and treated with melatonin (0.1-2.0 mM; cat. no. M5250-1G; Sigma-Aldrich; Merck KGaA) according to previously described protocols $(19,46-49)$. Subsequently, cell viability was detected by performing MTT and CCK-8 assays. For MTT assay, the plate was incubated for an additional $4 \mathrm{~h}$ at $37^{\circ} \mathrm{C}$, and crystal formazan was dissolved in DMSO $(0.2 \mathrm{ml} /$ well). The absorbance of each well was measured using a microplate reader at wavelengths of $570 \mathrm{~nm}$. For the CCK-8 assay, the 96-well plates were incubated for $4 \mathrm{~h}$ at $37^{\circ} \mathrm{C}$, and the absorbencies at each time point were measured at $450 \mathrm{~nm}$ by a microplate reader. Melatonin at $2 \mathrm{mM}$ was selected for subsequent experiments, as this concentration significantly reduced cell viability compared with other concentrations.

Colony formation assay. HCT116 and LoVo CRC cells were pretreated with $2 \mathrm{mM}$ melatonin for $48 \mathrm{~h}$ at $37^{\circ} \mathrm{C}$. Subsequently, cells were seeded $\left(1 \times 10^{3}\right.$ cells/well $)$ into a 6 -well plate. After 7 days, the colonies were fixed with $4 \%$ paraformaldehyde for $30 \mathrm{~min}$ at room temperature and then stained with $0.1 \%$ crystal violet (Beijing Solarbio Science \& Technology Co., Ltd.) for $20 \mathrm{~min}$ at room temperature. Colonies were observed with scanner $(50,51)$. Colonies containing $>50$ cells were counted.

EdU labelling and staining. HCT116 and LoVo CRC cells $\left(5 \times 10^{5}\right.$ cells/well $)$ were plated into 96 -well plates. EdU $(50 \mu \mathrm{M})$ from the Cell-Light ${ }^{\mathrm{TM}}$ EdU Apollo488 kit (Guangzhou RiboBio Co., Ltd.) was used for labelling for $24 \mathrm{~h}$ at $37^{\circ} \mathrm{C}$. Following fixation with $4 \%$ paraformaldehyde for $30 \mathrm{~min}$ at room temperature, cells were stained with Apollo and Hoechst 33342 for $30 \mathrm{~min}$ at room temperature in the dark. Stained cells were visualized using a DMI6000 B inverted fluorescence microscope (Leica Microsystems $\mathrm{GmbH}$ ). The number of stained cells was determined according to the manufacturer's protocol.

Cell apoptosis analysis. HCT116 and LoVo CRC cells were pretreated with $2 \mathrm{mM}$ melatonin for $48 \mathrm{~h}$ at $37^{\circ} \mathrm{C}$. The apoptosis rate was evaluated using the Annexin V-FITC/PI Apoptosis Detection kit (C1062; Beyotime Institute of Biotechnology) according to the instructions from the manufacturer. Following treatment, the cells were collected, washed with PBS, and resuspended in $195 \mu \mathrm{l}$ binding buffer. Then, $5 \mu \mathrm{l}$ Annexin V-FITC and $10 \mu \mathrm{l}$ PI were added to the buffer and incubated at room temperature for $20 \mathrm{~min}$ in the dark. Early and late apoptotic cells were analyzed using a CytoFLEX S flow cytometer and CytExpert 2.3 software (Beckman Coulter, Inc.).

Cell transfection. HCT116 and LoVo CRC cells were seeded at $5 \times 10^{5}$ cells/well in 6 -well plates. The cells were transfected using $5 \mu$ l Lipofectamine ${ }^{\circledR} 2000$ RNAiMAX (Invitrogen; Thermo Fisher Scientific, Inc.) for $20 \mathrm{~min}$ at room temperature with a mixture comprising $500 \mu \mathrm{l} \mathrm{FBS-free} \mathrm{medium}$ with $10 \mu \mathrm{l}$ miR-34a inhibitor (MIMAT0000255; $100 \mathrm{nM}$; Guangzhou RiboBio Co., Ltd.) or $10 \mu \mathrm{l}$ of miR-449a inhibitor (MIMAT0001541; 100 nM; Guangzhou RiboBio Co., Ltd.) or the negative control (Guangzhou RiboBio Co., Ltd.) according to the manufacturer's instructions. The mixture was added to 
each well for $6 \mathrm{~h}$ at $37^{\circ} \mathrm{C}$. The mixture was changed for fresh medium after $6 \mathrm{~h}$. Cells were treated with melatonin after transfection for $24 \mathrm{~h}$.

$R N A$ extraction and reverse transcription-quantitative $P C R$ $(R T-q P C R)$. Total RNA was extracted from the HCT116 and LoVo CRC cells using TRIzol ${ }^{\circledR}$ reagent (Thermo Fisher Scientific, Inc.). cDNA was synthesized with a RevertAid ${ }^{\mathrm{TM}}$ First Strand cDNA Synthesis kit (Thermo Fisher Scientific, Inc.) with the following thermocycling conditions: $42^{\circ} \mathrm{C}$ for $1 \mathrm{~h}$; followed by $75^{\circ} \mathrm{C}$ for $5 \mathrm{~min}$ and $4^{\circ} \mathrm{C}$ forever. Subsequently, qPCR was performed to determine the expression levels of hsa-miR-125a, hsa-miR-365a, hsa-miR-34a, hsa-miR-449a, hsa-miR-184, hsa-miR-143a, Bcl-2 and Notch1. qPCR was performed with SYBR-Green Realtime PCR Master Mix (Toyobo Life Science) on a CFX96 ${ }^{\mathrm{TM}}$ Real-Time System (Bio-Rad Laboratories, Inc.) with the following thermocycling conditions: $95^{\circ} \mathrm{C}$ for $10 \mathrm{~min}$; followed by 40 cycles at $95^{\circ} \mathrm{C}$ for $15 \mathrm{sec}$ and $60^{\circ} \mathrm{C}$ for $60 \mathrm{sec}$. The sequences of the primers used for qPCR are presented in Table SI. miRNA and mRNA expression levels were quantified using the ${ }^{2-\Delta \Delta C q}$ method and normalized to the internal reference genes U6 and actin, respectively (52).

Western blotting. HCT116 and LoVo CRC cells were lysed in RIPA buffer (Beyotime Institute of Biotechnology) to obtain total protein, and total protein concentration was quantified using a BCA protein assay kit (Beyotime Institute of Biotechnology). An equal amount of total protein $(30 \mu \mathrm{g})$ was subjected to $10 \%(\mathrm{w} / \mathrm{v})$ SDS-PAGE gel and transferred onto PVDF membranes (EMD Millipore). These membranes were blocked with 5\% skimmed milk for $2 \mathrm{~h}$ at room temperature. Subsequently, the membranes were incubated overnight at $4^{\circ} \mathrm{C}$ with the primary antibodies targeted against: cleaved caspase-3 (1:1,000; cat. no. 9661; Cell Signaling Technology, Inc.), Notch1 (1:1,000; cat. no. 3447; Cell Signaling Technology, Inc.), cleaved poly (ADP-ribose) polymerase 1 (PARP; 1:1,000; cat. no. ab203467; Abcam), p53 (1:1,000; cat. no. 10442-1-AP; ProteinTech Group, Inc.), Bcl-2 (1:1,000; cat. no. sc-7382; Santa Cruz Biotechnology, Inc.) and $\beta$-actin (1:1,000; cat. no. HC201; TransGen Biotech Co., Ltd.). After washing, the membranes were incubated with Goat Anti-Mouse IgG (H+L) HRP-conjugated (1:5,000; cat. no. HS201-01; TransGen Biotech Co., Ltd.), Goat Anti-Rabbit IgG (H+L) HRP-conjugated (1:5,000; cat. no. HS101-01; TransGen Biotech Co., Ltd.) secondary antibodies and Goat Anti-Rat IgG (H+L) Secondary Antibody, HRP (1:5,000; cat. no. 31470; Thermo Fisher Scientific, Inc.) for $1 \mathrm{~h}$ at room temperature. Protein bands were visualized using Immobilon ${ }^{\mathrm{TM}}$ Western Chemiluminescent Horseradish Peroxidase Substrate (EMDMillipore). Protein expression levels were semi-quantified using ImageJ software (v1.46, National Institutes of Health) with $\beta$-actin as the loading control.

Luciferase reporter assay. Human Bcl-2 and Notch1 3'UTR regions containing the putative binding sites of miR-34a/449a were subcloned into the pGL3 promoter (Promega Corporation) using $\mathrm{XbaI}$ restriction digest sites at the end of the oligonucleotides. HCT116 CRC cells $\left(1.5 \times 10^{4}\right.$ cells/well) were seeded into a 24 -well plate in triplicate. CRC cells were co-transfected with 400 ng pGL3-3'UTR-Promoter plasmid, 100 ng Renilla (Promega Corporation) and 100 nM miR-34a or miR-449a inhibitor using Lipofectamine 2000 (Invitrogen; Thermo Fisher Scientific, Inc.). At 48 h post-transfection, luciferase activities were determined using a Dual Luciferase Reporter assay kit (Promega Corporation). Firefly luciferase activities were normalized to Renilla luciferase activities.

Tumorigenesis in xenograft models. Female BALB/c Nude

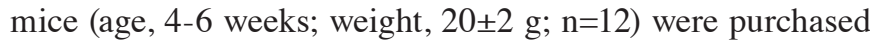
from GemPharmatech Co., Ltd. All animals were housed in cages at $24^{\circ} \mathrm{C}$ with 12 -h light/dark cycles, $50-70 \%$ humidity, and free access to food and water. All experiments were approved by the Ethics Committee on Animal Experiments of the Medical School of Shandong University [approval no. KYLL-2017(KS)-357]. Nude mice were injected subcutaneously into the right shoulder with $6 \times 10^{6}$ HCT 116 cells suspended in $150 \mu \mathrm{l}$ PBS. When tumors reached an average volume of $50 \mathrm{~mm}^{3}$, the mice were randomly divided into two groups ( $n=6 /$ group): i) Control group (same volume of PBS as the melatonin group) and ii) melatonin group $(25 \mathrm{mg} / \mathrm{kg}$; intraperitoneal injection daily for 23 days). The $25 \mathrm{mg} / \mathrm{kg}$ melatonin was selected for xenograft assays according to previous studies (53-55). The tumors were isolated, measured and histologically confirmed. The perpendicular tumor dimensions (a, length and b, width) were measured using Vernier caliper to calculate the volume $\left(\mathrm{V} ; \mathrm{mm}^{3}\right)$ according to the following formula: $V=\left(a_{x} b^{2}\right) / 2$. Mice were anesthetized with an intraperitoneal injection of $50 \mathrm{mg} / \mathrm{kg}$ sodium pentobarbital (1\%). The tumors were removed and the tissue specimens were used for immunofluorescence analysis. After sampling, the mice were euthanized with an overdose of sodium pentobarbital $(100 \mathrm{mg} / \mathrm{kg})(55)$.

$H E$ staining. The tumor sections were cut at a thickness of $4 \mu \mathrm{m}$ using a microtome. The sections were dewaxed using xylene and rehydrated in ethanol with gradient concentrations $(100,95,90,80,70,50$ and $30 \%)$ for $5 \mathrm{~min}$ at room temperature. After being washed with distilled water for 5 min, Hematoxylin (cat. no. C0107; Beyotime Institute of Biotechnology) was added dropwise to stain the tissue for $15 \mathrm{~min}$. The stained tissue was placed in $1 \%$ hydrochloric acid ethanol (Merck KGaA) for differentiation for $10 \mathrm{sec}$. Then, 0.25\% Eosin dye (cat. no. C0109; Beyotime Institute of Biotechnology) solution was added for counterstaining for 5 min and tissues were dehydrated by soaking in gradient concentration alcohol (70, 80, 90, 95 and $100 \%$ ethanol) for $5 \mathrm{~min}$. All these steps were performed at room temperature. The sections were observed (magnification, x20) and images captured under the optical microscope. Each section was divided into three columns, and three images captured of each column, nine images per section.

Immunofluorescence staining. Cancer tissues obtained from the mouse xenograft model were fixed using $4 \%$ paraformaldehyde for $48 \mathrm{~h}$ at $4^{\circ} \mathrm{C}$. The tumor sections were cut at a thickness of $10 \mu \mathrm{m}$ using a freezing microtome. The sections were blocked and permeabilized in $5 \%$ goat serum (cat. no. ZLI-9021; OriGene Technologies, Inc.) solution containing $0.3 \%$ Triton $\mathrm{X}-100$ for $2 \mathrm{~h}$ at room temperature. The sections 
were incubated with a rabbit anti-Ki-67 primary antibody (1:400; cat. no. ab16667; Abcam) overnight at $4^{\circ} \mathrm{C}$. The sections were washed in PBS three times and incubated with Dylight 594, Goat Anti-Rabbit IgG (1:1,000; cat. no. A23420; Abbkine Scientific Co., Ltd.) secondary antibodies for $1 \mathrm{~h}$ at room temperature. TUNEL assay was performed using the TransDetect ${ }^{\circledR}$ in situ Fluorescein TUNEL Cell Apoptosis Detection kit (cat. no. FA201; TRANS). Briefly, the sections were blocked and permeabilized in 5\% goat serum solution containing $0.3 \%$ Triton $\mathrm{X}-100$ for $2 \mathrm{~h}$ at room temperature. The sections were incubated with a mix of $1 \mathrm{X}$ labeling solution and $\operatorname{TdT}(25: 1)$ for $1 \mathrm{~h}$ at $37^{\circ} \mathrm{C}$ in the dark. Nuclei were stained with DAPI (Sigma-Aldrich; Merck KGaA) for 15 min at room temperature. Stained samples were observed (TUNEL magnification, x20; Ki-67 magnification, x10) using a confocal microscope (Leica Microsystems GmbH). Each section was divided into three columns, and three images captured of each column, nine images per section.

Bioinformatics analysis. The sequences of the microRNAs were searched through miRBase (http://www.mirbase.org/). The downstream target genes of the microRNAs cluster were predicted with TargetScan (http://www.targetscan.org/vert_71/).

Statistical analyses. Data are presented as the mean \pm standard deviation of at least three independent experiments. Statistical analyses were performed using GraphPad Prism software (version 8; GraphPad Software, Inc.). Comparisons between two groups were analyzed using the unpaired Student's t-test. Comparisons among multiple groups were analyzed using one-way ANOVA followed by Dunnett's post hoc test. $\mathrm{P}<0.05$ was considered to indicate a statistically significant difference.

\section{Results}

Melatonin suppresses CRC cell proliferation and viability. The effect of melatonin on CRC cell viability (HCT116, LoVo, SW480, SW620, HT-29 and DLD-1) following treatment for 24 or $48 \mathrm{~h}$ was assessed by performing an MTT assay. The results indicated that melatonin $(0.1-2.0 \mathrm{mM})$ significantly inhibited CRC cell viability in a time- and dose-dependent manner. Compared with the control group, SW480 and SW620 cell viability was inhibited by treatment with $1 \mathrm{mM}$ melatonin for $48 \mathrm{~h}$, whereas DLD-1 cell viability was inhibited by treatment with $2 \mathrm{mM}$ melatonin for $48 \mathrm{~h}$. HCT116 and LoVo cell viability were significantly reduced compared with SW480, SW620, HT-29 and DLD-1 CRC cell lines at 24 and 48 h (Fig. 1A). The effect of melatonin on HCT116 and LoVo cell proliferation was assessed by performing EdU staining and counting the number of EdU ${ }^{+}$cells (Fig. 1B and C). Compared with the control group, the number of EdU ${ }^{+}$cells in the melatonin group was significantly reduced. The colony formation ability of HCT116 and LoVo cells following treatment with melatonin was also assessed (Fig. 1D and E). The number of colonies in the melatonin group was also significantly reduced compared with the control group.

Melatonin induces CRC cell apoptosis. To verify the effect of melatonin on HCT116 and LoVo cell apoptosis, Annexin V/PI staining was conducted and the number of apoptotic cells was determined via flow cytometry (Fig. 2A and B). Compared with the control group, the number of apoptotic cells in the melatonin group was significantly increased. The expression of apoptosis-related proteins cleaved caspase-3 and cleaved PARP was determined via western blotting (Fig. 2C and D). The results indicated that the apoptotic rate of melatonin-treated cells was significantly higher compared with the control group.

Melatonin inhibits tumor growth in vivo. A nude mouse tumorigenesis model was established to assess the inhibitory effect of melatonin on tumor growth in vivo. Compared with the control group, the tumors in the melatonin group were notably smaller (Fig. 3A). During the tumor-bearing period, the tumor growth in the melatonin-treated group was clearly slower compared with the control group, and the corresponding tumor volume was smaller (Fig. 3B and C). The tumor weight of the two groups was assessed at the end of the experiments, and the results demonstrated that the average weight of tumors in the melatonin group was significantly lower compared with the control group (Fig. 3D). Hematoxylin and eosin staining was performed and the results indicated that the melatonin group displayed an increased number of tissues with tumor cell necrosis compared with the control group (Fig. 3E). Finally, tumor cell proliferation was determined by performing Ki-67 staining. Tumor cell proliferation was notably inhibited in the melatonin group compared with the control group (Fig. 3F). TUNEL staining was also performed to assess tumor cell apoptosis, which indicated that the melatonin group displayed obviously increased levels of apoptosis compared with the control group (Fig. 3G).

Melatonin affects CRC cell proliferation and apoptosis by regulating the expression of the miR-34a/449a cluster. Whether the aforementioned results were related to miRNA expression was assessed. First, the expression of a series of miRNAs (miR-125a, miR-365a, miR-34a, miR-449a, miR-184 and miR-143a) in HCT116 cells treated with $2 \mathrm{mM}$ melatonin for $48 \mathrm{~h}$ was assessed via RT-qPCR. HCT116 cell viability and apoptosis were significantly changed compared with other cell lines. All of the aforementioned miRNAs have been reported to be associated with CRC cell proliferation and apoptosis $(36,38,56,57)$. The results of the present study demonstrated that only miR-34a and miR-449a expression levels were significantly altered by melatonin treatment compared with the control group (Fig. 4A). Melatonin increased the expression levels of miR-34a and miR-449a in a concentration-dependent manner. miR-34a is a transcriptional target of p53 (58). Therefore, the expression of p53 in CRC cells treated with melatonin for $48 \mathrm{~h}$ was assessed via western blotting. Compared with the control group, melatonin markedly increased p53 expression levels in a concentration-dependent manner (Fig. S1). miR-34a and miR-449a belong to the same family, and work together as a complex, termed the miR-34a/449a cluster (59). To further investigate whether the increased expression of the miR-34a/449a cluster was related to altered CRC cell proliferation and apoptosis, endogenous expression of the miR-34a/449a cluster was downregulated by transfecting cells with an miR-34a/449a cluster inhibitor. The transfection efficiency of the miR-34a/449a cluster inhibitor is presented in Fig. 4B. The effect of the miR-34a/449a cluster on CRC cell viability 
A
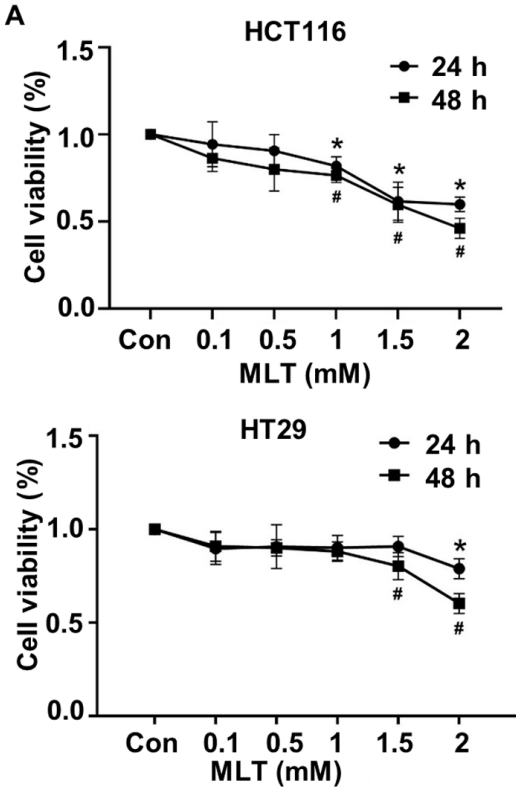

B
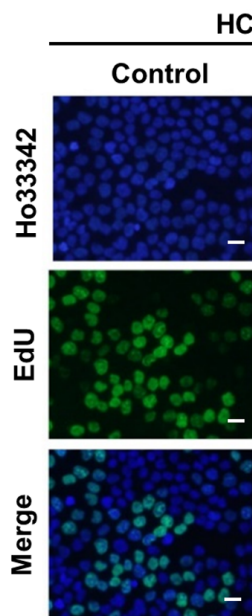

D

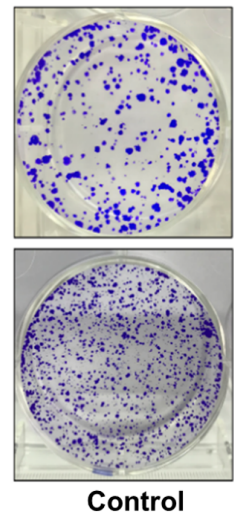

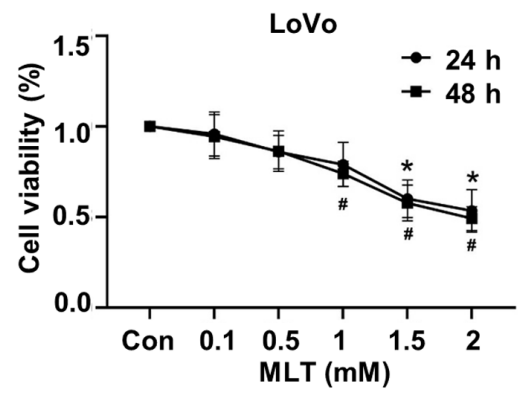
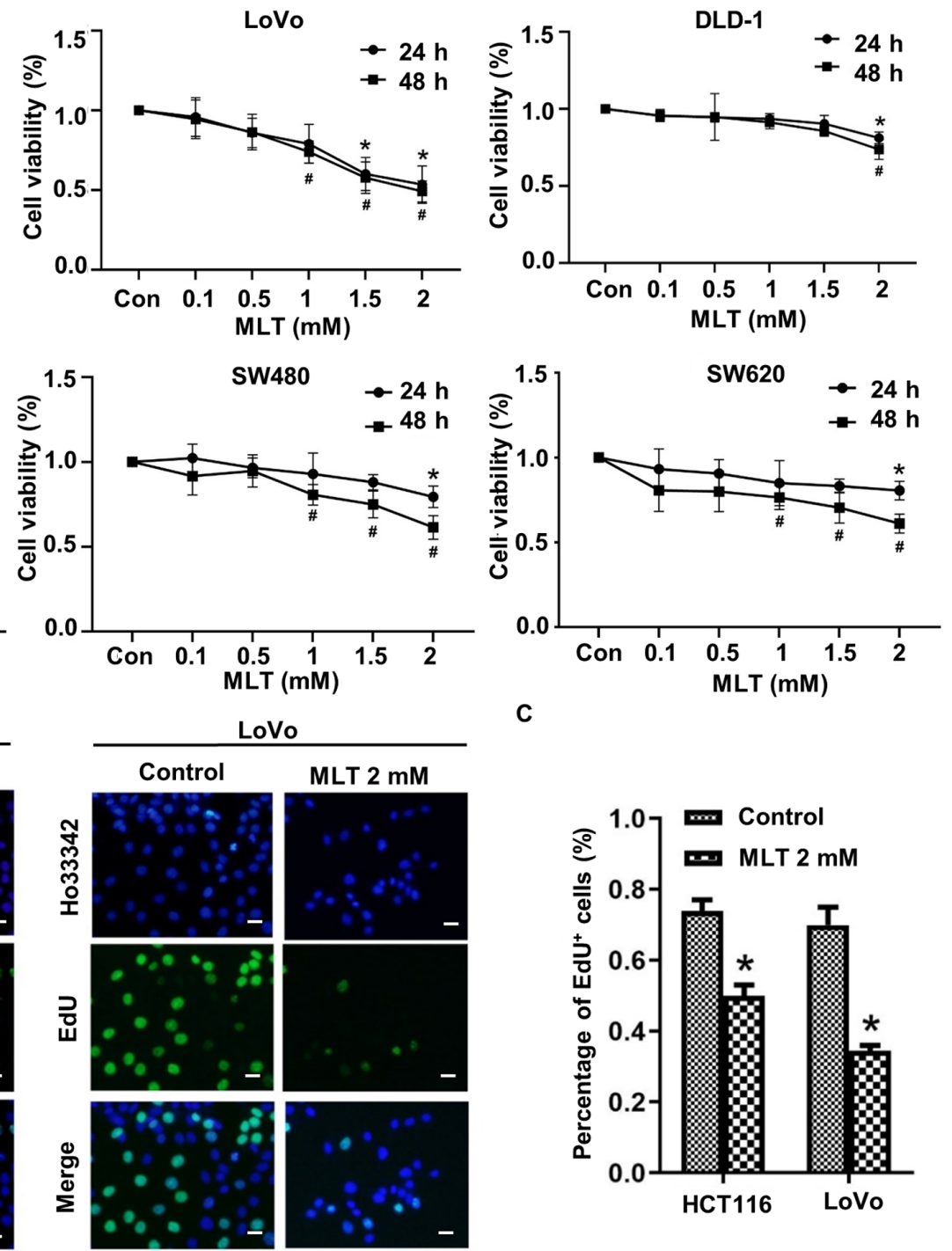

C

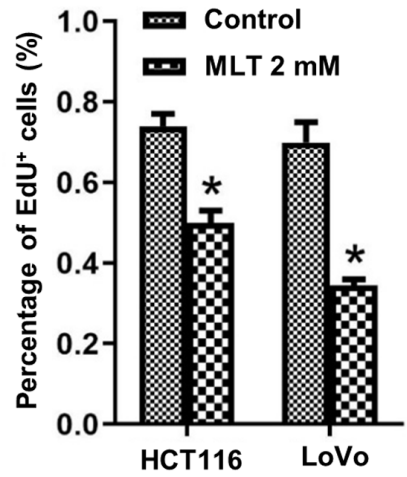

Figure 1. Melatonin suppresses CRC cell viability and proliferation. (A) HCT116, LoVo, SW480, SW620, HT-29 and DLD-1 CRC cells were treated with 0.1, 0.5, $1,1.5$ or $2 \mathrm{mM}$ melatonin for 24 or $48 \mathrm{~h}$. Cell viability was assessed by performing an MTT assay. ${ }^{*} \mathrm{P}<0.05 \mathrm{vs}$. $24 \mathrm{~h}$ control; ${ }^{*} \mathrm{P}<0.05 \mathrm{vs}$. $48 \mathrm{~h}$ control. Following treatment with melatonin for $48 \mathrm{~h}, \mathrm{HCT} 116$ and LoVo CRC cell proliferation was assessed by (B) performing EdU staining (scale bar, $50 \mu \mathrm{m})$ and (C) quantified by counting the number of EdU ${ }^{+}$cells. Following treatment with melatonin for $48 \mathrm{~h}, \mathrm{CRC}$ cell proliferation was assessed by (D) performing colony formation assays and (E) quantified. ${ }^{*} \mathrm{P}<0.05$ vs. control. Data are presented as the mean \pm standard deviation. CRC, colorectal cancer; Con, control; MLT, melatonin.

and proliferation was assessed by performing CCK-8 and EdU staining assays, respectively. Compared with the control group, CRC cell viability and proliferation were significantly decreased in the melatonin group (Fig. 4C-E). However, in CRC cells pretreated with inhibitor and then treated with melatonin, the inhibitory effect of melatonin on CRC cell viability and proliferation was significantly weakened to a certain degree. Finally, the effect of the miR-34a/449a cluster on CRC cell apoptosis was assessed via flow cytometry. Pretreatment with the inhibitor significantly weakened the effect of melatonin on CRC cell apoptosis (Fig. 4F and G). The results suggested that melatonin inhibited viability and proliferation, and promoted 

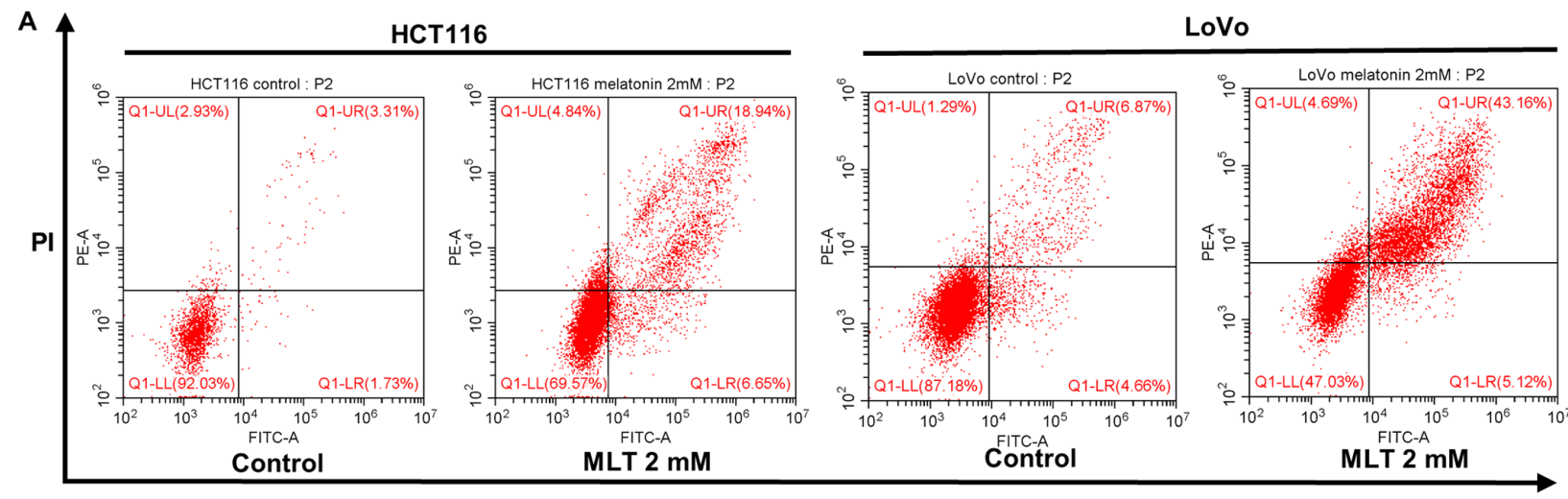

B

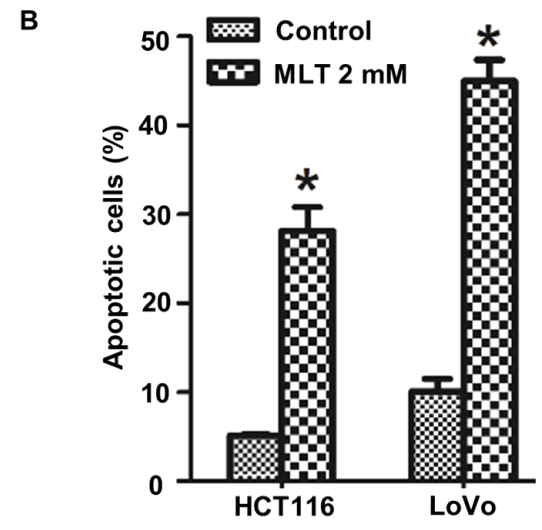

C

Annexin V
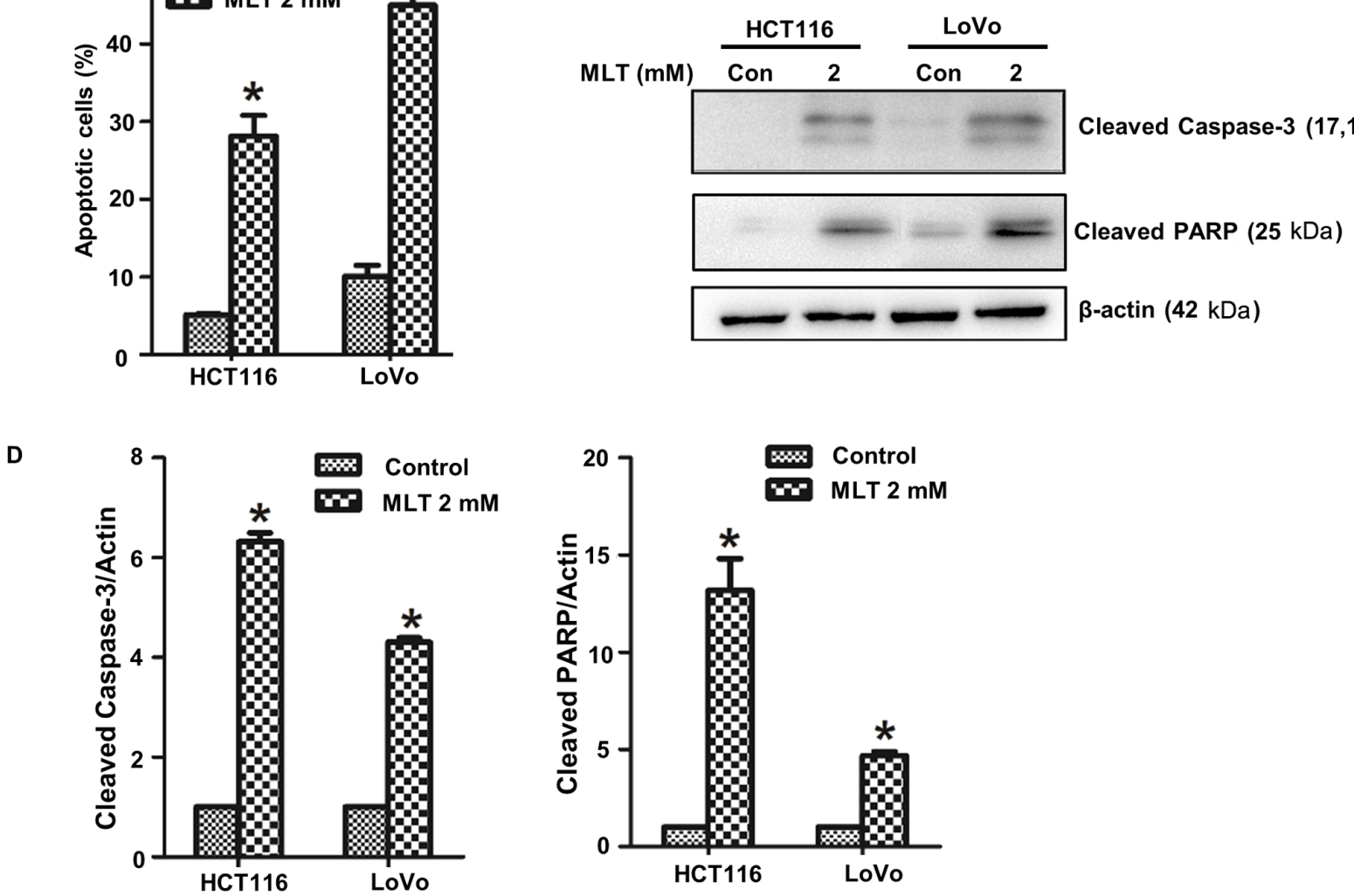

Figure 2. Melatonin induces CRC cell apoptosis. HCT116 and LoVo CRC cells were treated with $2 \mathrm{mM}$ melatonin for 48 h. Cell apoptosis was (A) determined via flow cytometry following Annexin V/PI staining and (B) quantified. Cleaved caspase-3 and cleaved PARP protein expression levels were (C) determined via western blotting and (D) semi-quantified. "P<0.05 vs. control. Data are presented as the mean \pm standard deviation. CRC, colorectal cancer; PARP, poly(ADP-ribose) polymerase 1; MLT, melatonin; Con, control.

apoptosis in CRC cells by upregulating the expression of the miR-34a/449a cluster.

Bcl-2 and Notchl are direct target genes of the miR-34a/449a cluster. To further investigate how the miR-34a/449a cluster exerted its regulatory function in melatonin-induced antiproliferative and proapoptotic activities in CRC cells, the downstream target genes of the miR-34a/449a cluster were determined by performing bioinformatics analysis with TargetScan (http://www.targetscan.org/vert_71/). It was predicted that the miR-34a/449a cluster bound to the 3'UTRs of Bcl-2 and Notch1 (Fig. 5A). pGL3-promoter-Bcl-2/Notch1 3'UTR vectors were constructed, and the relative luciferase activity was assessed using a dual-luciferase reporter assay.
miR-34a/449a cluster inhibition significantly increased the relative luciferase activity of pGL3-promoter-BCL2 3'UTR and pGL3-promoter-NOTCH1 3'UTR compared with the control (Fig. 5B and C), suggesting that Bcl-2 and Notch1 were direct target genes of the miR-34a/449a cluster. RT-qPCR and western blotting were performed to measure the mRNA and protein expression levels of Bcl-2 and Notch1 in melatonin-treated CRC cells, respectively. Compared with the control group, the mRNA and protein expression levels of Bcl-2 and Notch1 were notably downregulated by melatonin treatment (Fig. 5D and E). The RT-qPCR results demonstrated that miR-34a/449a cluster inhibition increased the mRNA expression levels of Bcl-2 and Notch1 in melatonin-treated CRC cells (Fig. 5F). The western blotting results were similar 
A

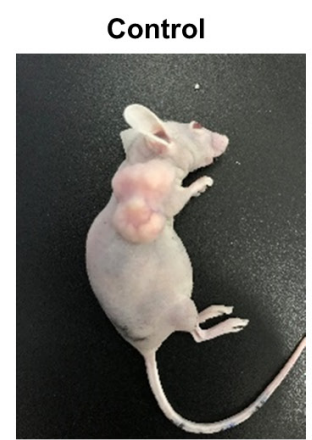

C

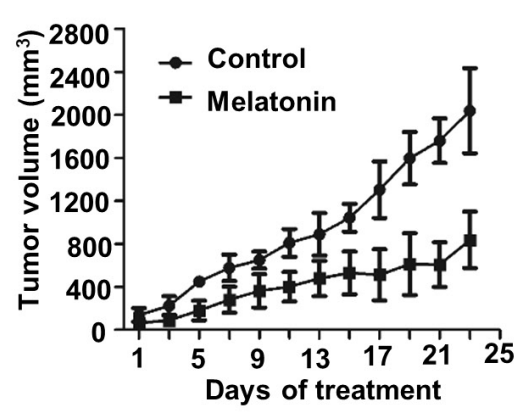

F
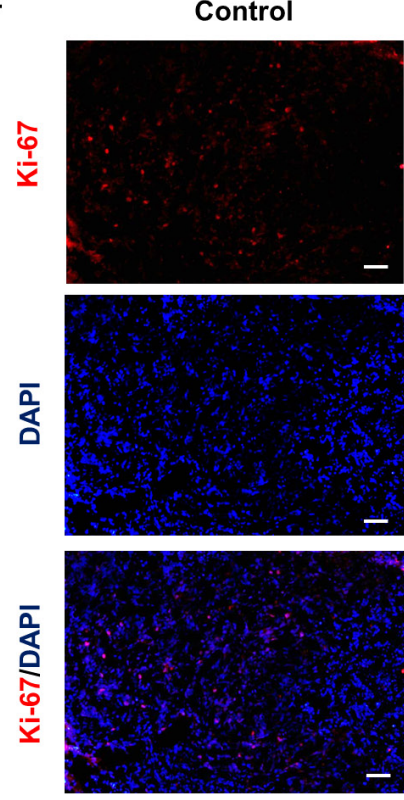

Melatonin
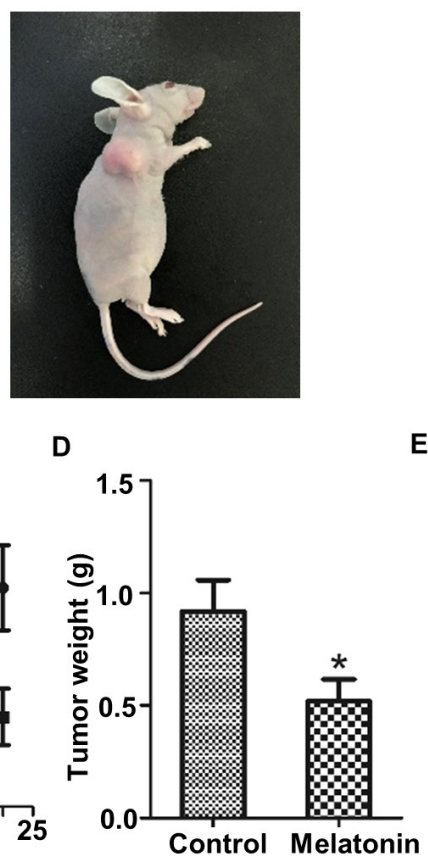

E
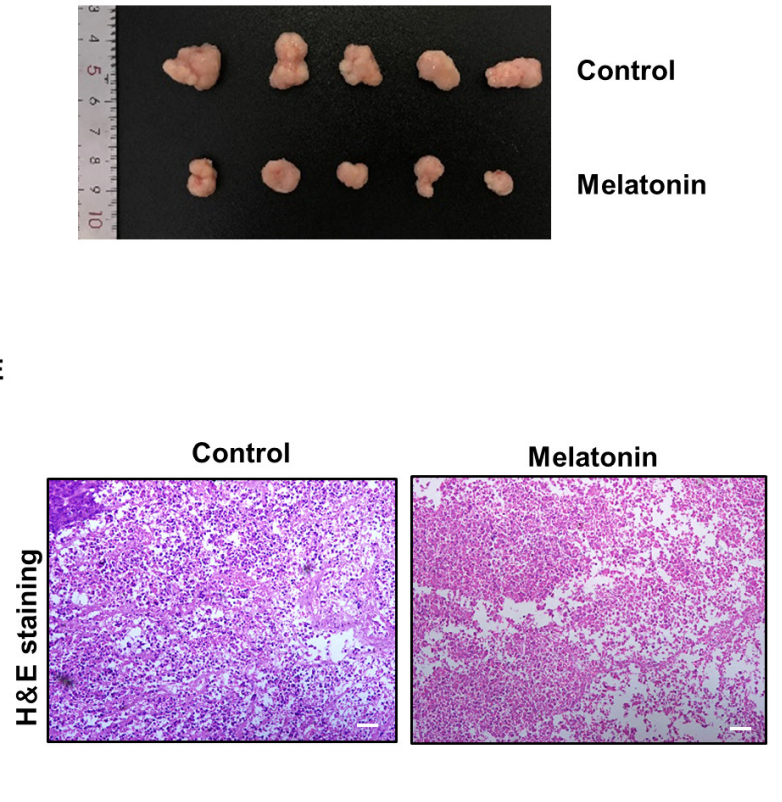

G
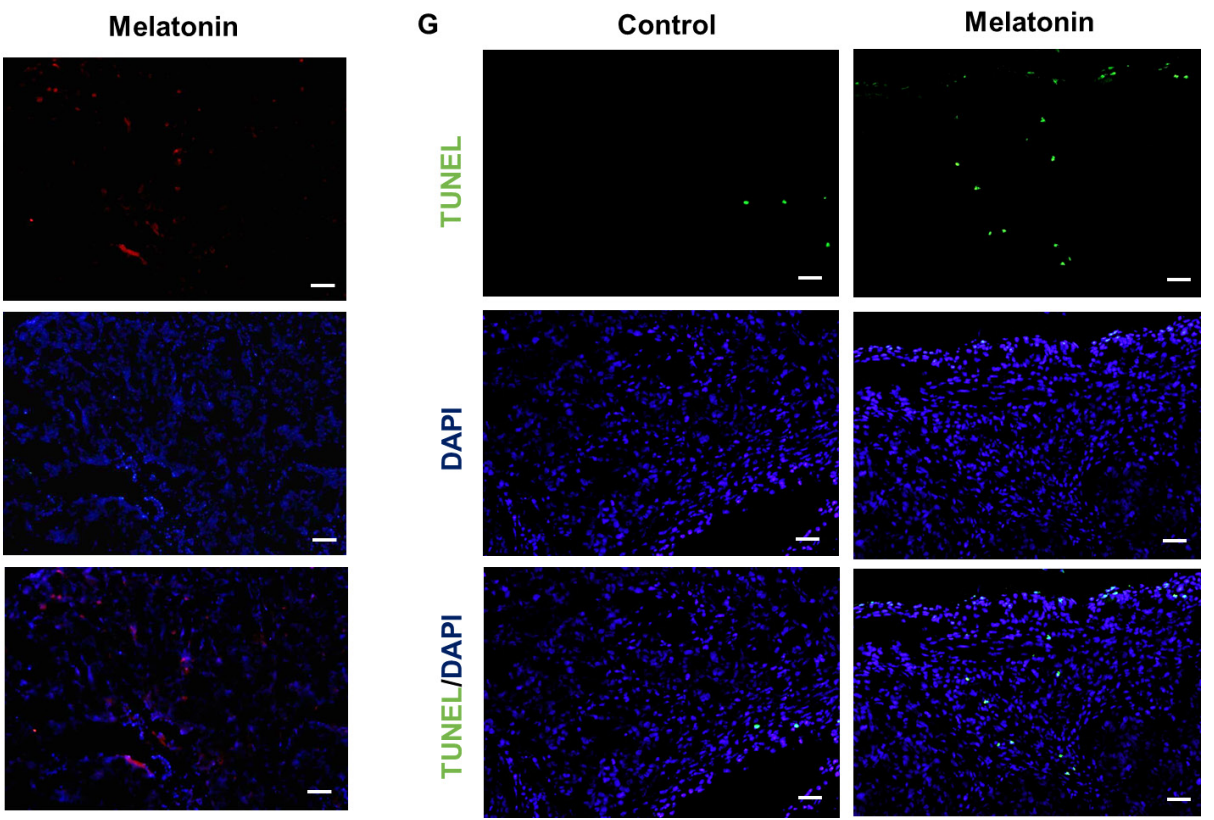

Figure 3. Melatonin inhibits tumor growth in vivo. Representative images of (A) tumor-bearing mice and (B) tumors on the day of harvesting. Tumor (C) volume and (D) weight. (E) Representative images of HE staining (scale bar, $50 \mu \mathrm{m}$ ). (F) Ki-67 staining was conducted to assess tumor cell proliferation (scale bar, $100 \mu \mathrm{m}$ ). (G) TUNEL staining was performed to assess tumor cell apoptosis (scale bar, $50 \mu \mathrm{m}$ ). "P<0.05 vs. control. Data are presented as the mean \pm standard deviation. HE, hematoxylin and eosin.

compared with melatonin group, the protein expression levels of Bcl-2 and Notch1 of miR inhibitor group were markedly upregulated following transfection with the miR-34a/449a cluster inhibitor (Fig. 5G). Collectively, the results indicated that the miR-34a/449a cluster bound to the 3'UTRs of Bcl-2 and Notch1 to negatively regulate their expression.

\section{Discussion}

CRC is one of the most common types of malignant cancer of the digestive system worldwide and is associated with high rates of morbidity and mortality $(1,2)$. In 2020 , the estimated new cases of colon cancer in the United States are 78,300 in men, and 69,650 in women, accounting for 8-9\% of all cancer cases (2). In $50 \%$ of patients with CRC, tumor recurrence is observed, even if the tumor tissue is excised prior to tumor cell metastasis (60). In addition, the effect of chemotherapeutic drugs on malignant colorectal tissue is reduced in advanced phases (61). A combinations of different agents may be used to overcome the limitations of these therapeutics; however, this can also result in increased side effects, off-target cytotoxicity and drug toxicity (62). Therefore, improved chemotherapeutic 

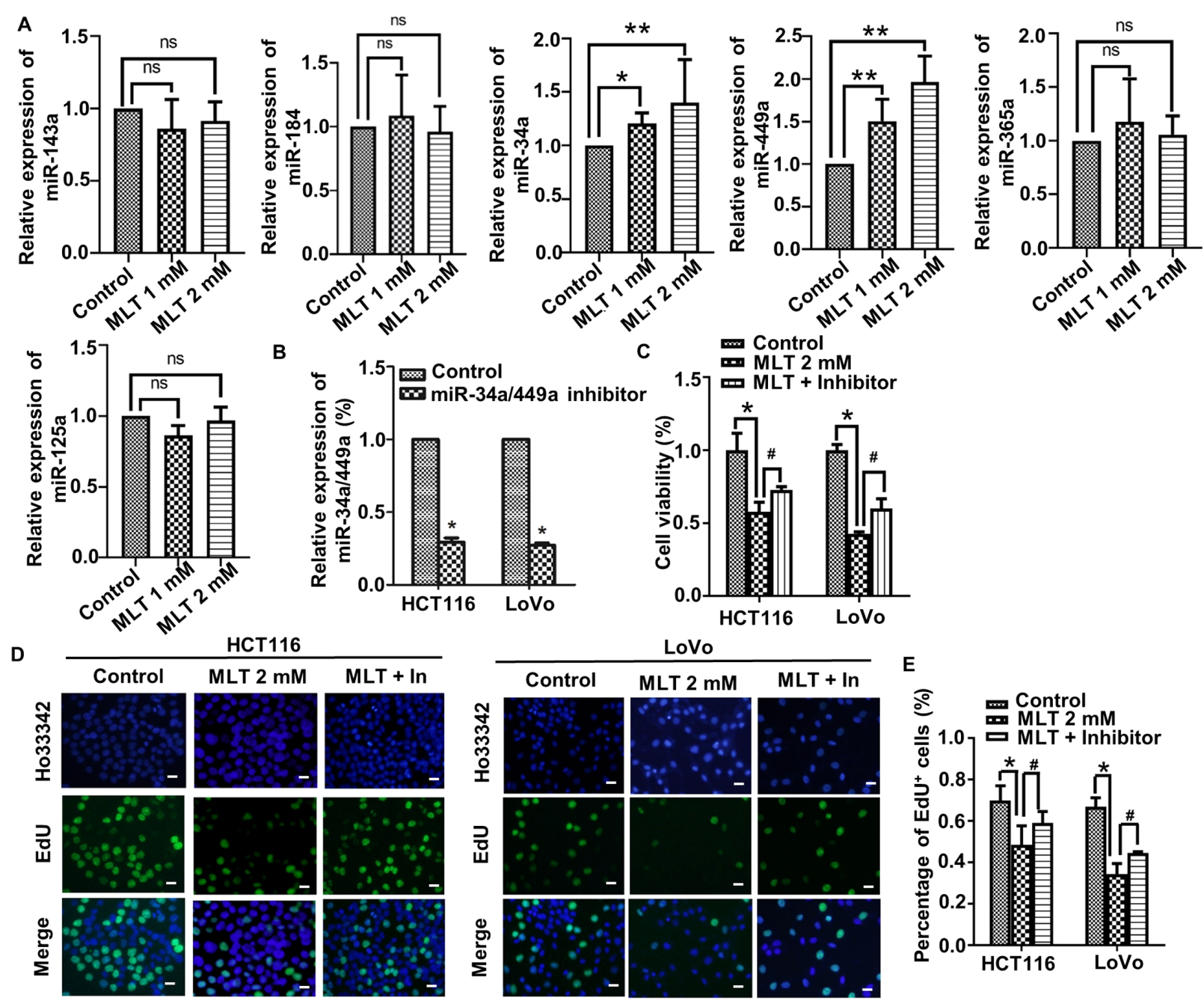

LoVo

$\mathbf{F}$

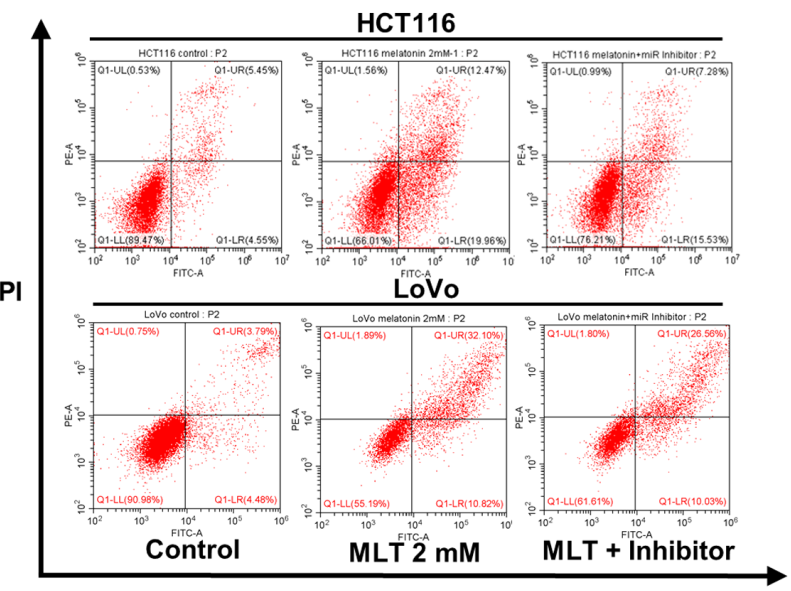

MLT $2 \mathrm{mM} \quad$ MLT + In

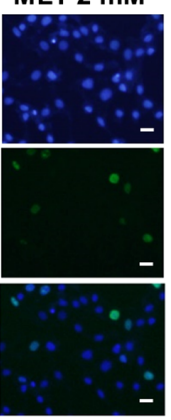

G

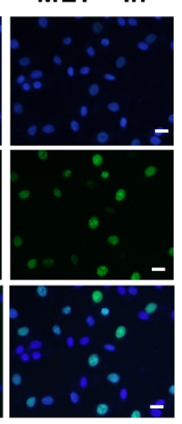

E
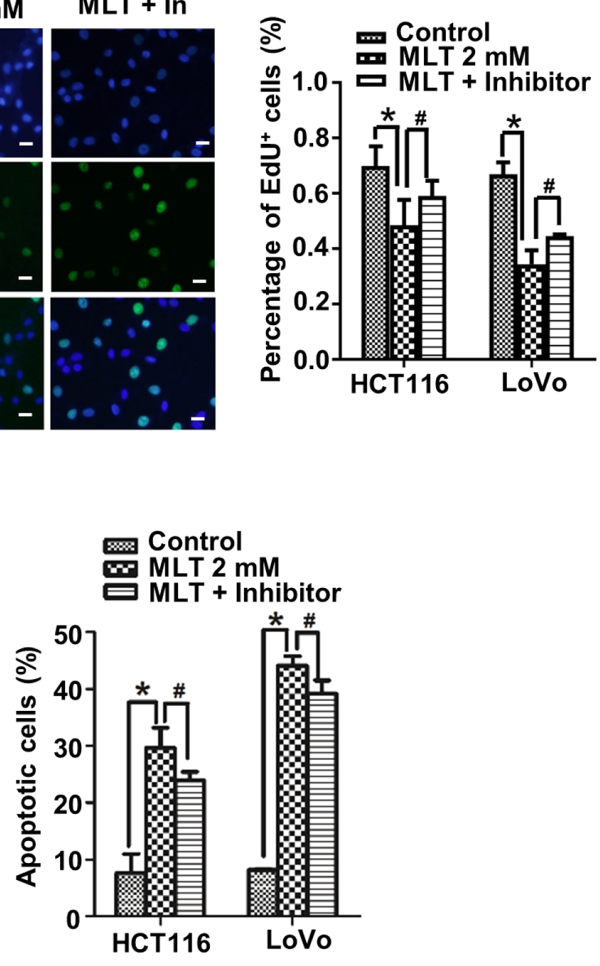

Annexin V

Figure 4. Melatonin affects CRC cell proliferation and apoptosis by regulating the expression of the miR-34a/449a cluster. HCT116 cells were treated with $2 \mathrm{mM}$ melatonin for $48 \mathrm{~h}$. (A) The expression levels of miR-125a, miR-365a, miR-34a, miR-449a, miR-184 and miR-143a was determined via reverse transcription-quantitative PCR. (B) The transfection efficiency of miR-34a/449a inhibitor in HCT116 and LoVo cells. "P<0.05 vs. control. (C) HCT116 and LoVo cell viability were detected using a Cell Counting Kit-8 assay. CRC cell proliferation was (D) determined by performing EdU staining (scale bar, $50 \mu \mathrm{m}$ ) and (E) the number of EdU ${ }^{+}$cells was quantified. CRC cell apoptosis was (F) determined via flow cytometry and (G) quantified. ${ }^{*} \mathrm{P}<0.05,{ }^{* *} \mathrm{P}<0.01$ and ${ }^{\text {"P}} \mathrm{P}<0.05$ vs. MLT $2 \mathrm{mM}$. Data are presented as the mean \pm standard deviation. CRC, colorectal cancer; miR, microRNA; ns, not significant; MLT, melatonin.

agents that display little to no unfavorable off-target effects need to be identified. Melatonin is a natural hormone that does not display toxicity and regulates numerous physiological processes, including the circadian rhythm and antioxidative processes $(63,64)$. An increasing number of studies have demonstrated that melatonin also possesses anticancer properties in several types of cancer $(65,66)$, for example, melatonin inhibits proliferation and invasion via repression of miRNA-155 in glioma cells (45). Melatonin restrains angiogenic factors in triple-negative breast cancer by targeting miR-152-3p in in vivo and in vitro studies (55). Moreover, melatonin possesses anticancer properties via various molecular 


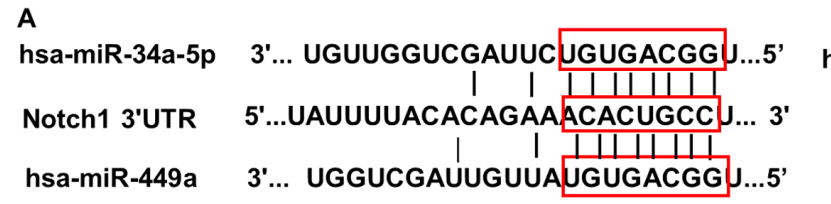

B

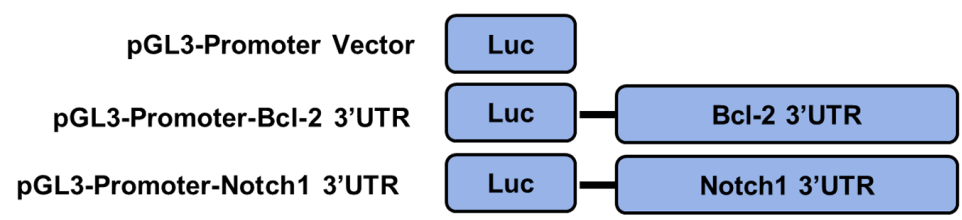

hsa-miR-34a-5p 3'... UGUUGGUCGAUUCUGUGACGGU...5' Bcl-2 3'UTR 5' ... UCGAAUCAGCUAUUU-ACUGCCAA... 3' hsa-miR-449a 3 '... UGGUCGAUUGUUAUGUGACGGU...5'
。

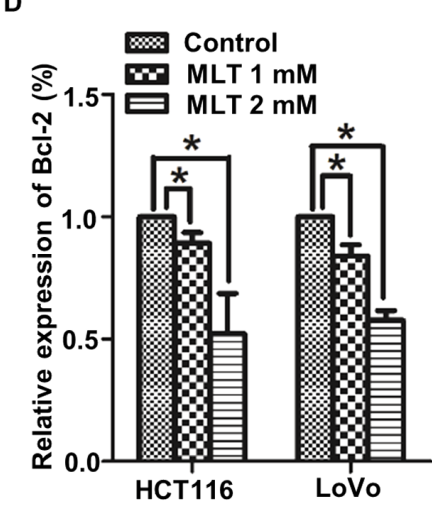

$\mathbf{F}$

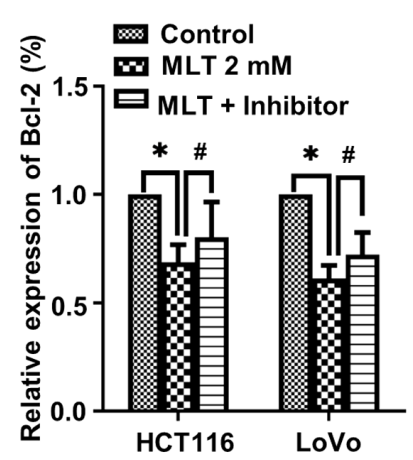

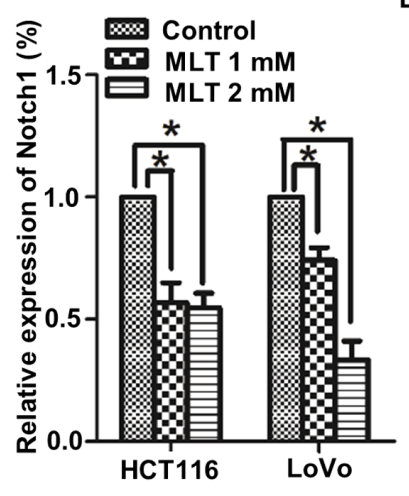

E

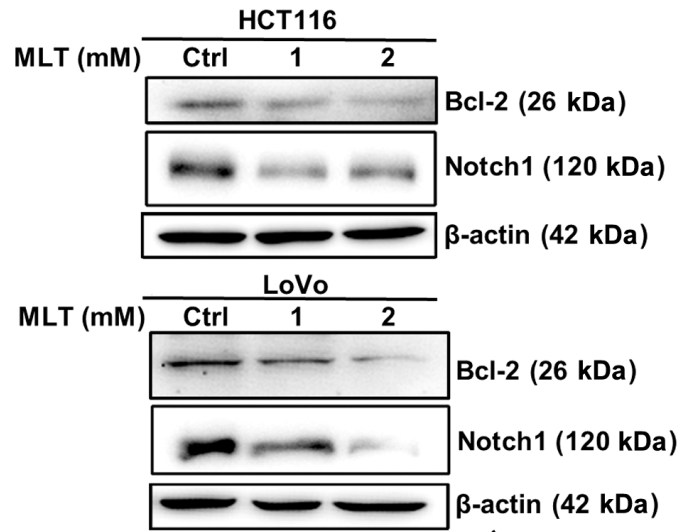

G

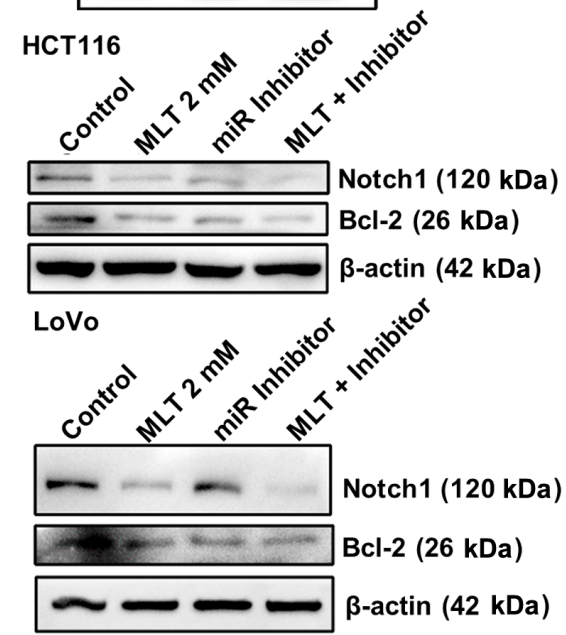

Figure 5. Bcl-2 and Notch1 are direct target genes of the miR-34a/449a cluster. (A) The predicted binding sequences between miR-34a/449a cluster and the 3'UTRs of Bcl-2 and Notch1. (B) Schematic illustration of the pGL3-promoter luciferase reporter constructs that were used for examining the effect of the miR-34a/449a cluster on the 3'UTRs of Bcl-2 and Notch1. (C) The dual luciferase reporter assay was performed to verify the interaction between the miR-34a/449a cluster and the 3'UTRs of Bcl-2 and Notch1. HCT116 and LoVo cells were treated with 1 or 2 mM melatonin for 48 h. Bcl-2 and Notch1 (D) mRNA and (E) protein expression levels were determined via RT-qPCR and western blotting, respectively. HCT116 and LoVo cells were pretreated with the miR-34a-449a cluster inhibitor and then treated with $2 \mathrm{mM}$ melatonin for $48 \mathrm{~h}$. Bcl-2 and Notch1 (F) mRNA and (G) protein expression levels were determined via RT-qPCR and western blotting, respectively. ${ }^{*} \mathrm{P}<0.05$ vs. control; ${ }^{*} \mathrm{P}<0.05$ vs. $2 \mathrm{mM}$ MLT. Data are presented as the mean \pm standard deviation. miR, microRNA; UTR, untranslated region; RT-qPCR, reverse transcription-quantitative PCR; MLT, melatonin; Luc, luciferase.

mechanisms in CRC cells (25,67-69), for example, melatonin reduces endothelin-1 expression and secretion in colon cancer cells through the inactivation of FoxO-1 and NF- $\kappa \beta$ (26); Melatonin inhibits colon cancer RKO cell migration by downregulating Rho-associated protein kinase expression via the p38/MAPK signaling pathway (69). To the best of our knowledge, the present study demonstrated for the first time that melatonin inhibited proliferation and viability, and induced apoptosis in CRC cells in vitro and in vivo via upregulating the expression of miR-34a/449a cluster, and suppressing Bcl-2 and Notch1 expression.

In the present study, CRC cell (HCT116, LoVo, SW480, SW620, HT-29 and DLD-1) viability following treatment with melatonin (0.1-2 mM) for 24 and $48 \mathrm{~h}$ was assessed. Compared 


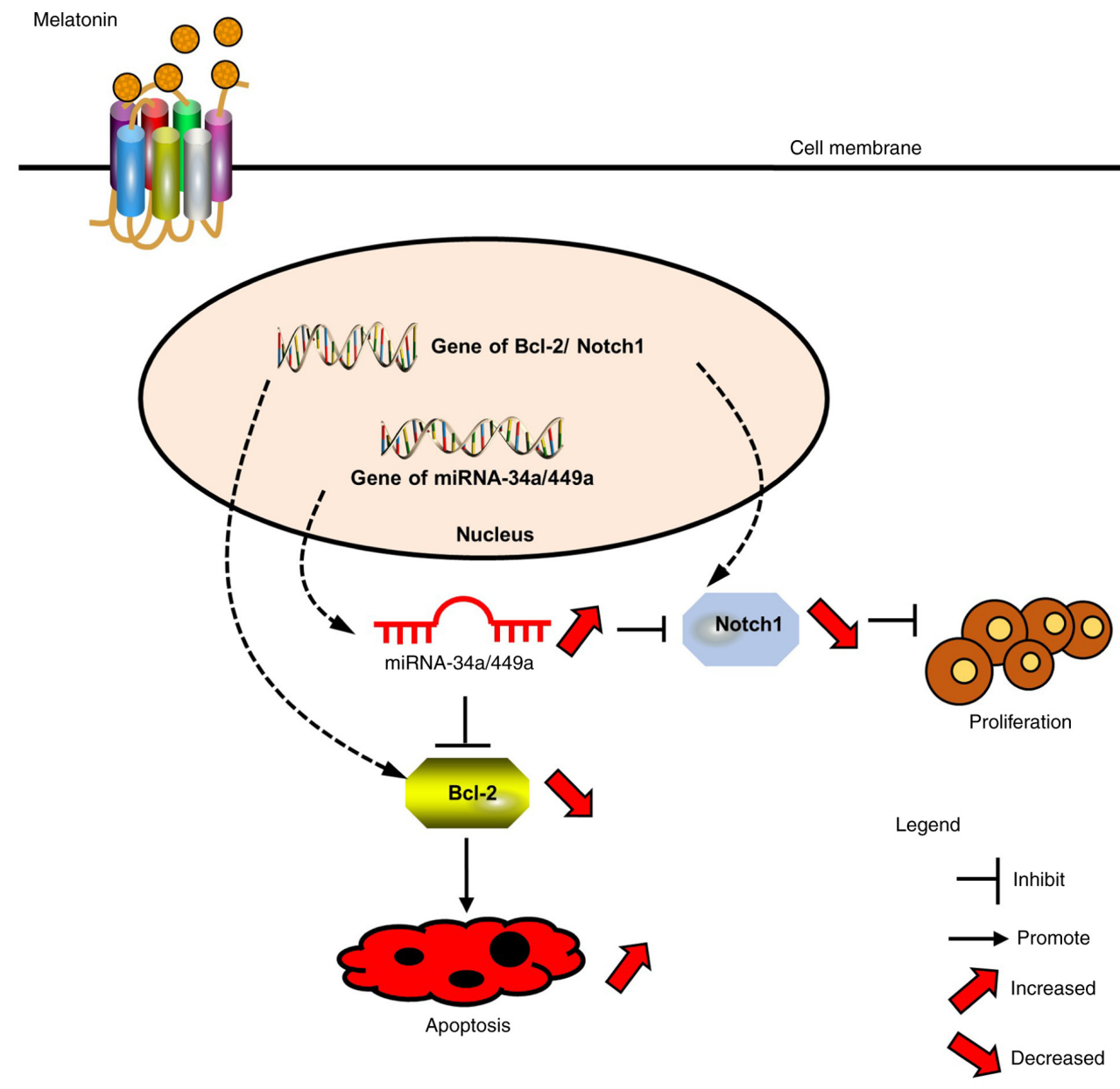

Figure 6. Schematic diagram of the mechanism underlying melatonin-mediated inhibition of proliferation and induction of apoptosis in colorectal cancer. miRNA, microRNA.

with the control group, SW480 and SW620 cell viability was inhibited by treatment with $1 \mathrm{mM}$ melatonin for $48 \mathrm{~h}$, whereas DLD-1 cell viability was inhibited by treatment with $2 \mathrm{mM}$ melatonin for $48 \mathrm{~h}$. The differences between the cell lines could be explained by differences in melatonin concentrations, cell types and experimental situations. Wei et al (70) reported that $2 \mathrm{mM}$ melatonin significantly suppressed LoVo cell proliferation following treatment for $48 \mathrm{~h}$ via histone deacetylase 4 nuclear import mediated by calcium/calmodulin dependent protein kinase II $\alpha$ alpha inactivation. León et al (26) reported that treatment of Caco-2 and T84 CRC cells for $72 \mathrm{~h}$ with $1 \mathrm{mM}$ melatonin induced cell cycle arrest at the G2/M phase. Riabykh et al (22), Farriol et al (23) and Anisimov et al (24) reported that melatonin inhibited CRC cell proliferation via decreasing DNA synthesis or promoting cell differentiation. In the present study, compared with the control group, HCT116 and LoVo cell viability was significantly inhibited by $50 \%$ following treatment with $2 \mathrm{mM}$ melatonin for $48 \mathrm{~h}$ via upregulation of the expression of the miR-34a/449a cluster. The aforementioned studies and the present study suggested that melatonin displayed a direct antitumor effect on CRC cells. Moreover, the results of the present study provided further evidence for the anticancer effects of melatonin, indicating that melatonin regulated the expression of miRNAs.

Although there are various mechanisms underlying melatonin-mediated inhibition of cell proliferation and promotion of cell apoptosis, the relationship between its effects is not completely understood. Trivedi et al (71) investigated the relationship among melatonin, colitis and malignant tumors using a colitis-associated colon carcinogenesis mice model. Their study was aimed at deciphering the effect of melatonin on autophagy and Nrf2 signaling pathways in a mouse model of colitis-associated colon carcinogenesis (CACC), and they focused on the relationship between melatonin and inflammation. However, this mice model did not study the relationship between melatonin and tumorigenesis directly. To verify the antitumor effects of melatonin in vivo, a xenograft mouse model was established and tumor cell proliferation and apoptosis were assessed in the present study and the results suggested that compared with the control group, melatonin inhibited proliferation and induced apoptosis in CRC cells, suggesting that melatonin may serve as a potential anti-CRC therapeutic.

miRNAs function as tumor oncogenes or suppressors, and serve a key role in the development and progression of cancer $(38,72,73)$. Melatonin results in upregulated miR-362-3p expression, and suppressed TNF- $\alpha$ induced protein 8 and neuropilin 2expression levels in breast cancer (74). Melatonin inhibited glioma cell proliferation and invasion via repression of miR-155 (45). Melatonin also inhibited gastric cancer cell proliferation by upregulating the expression of miR-16-5p (43). The aforementioned studies highlighted the critical roles of miRNAs in melatonin-induced attenuation of cancer growth. 
However, the association between melatonin and miRNAs in $\mathrm{CRC}$ is not completely understood. It has been reported that the members of miR-34 family are associated with tumor metastasis and growth (75,76). miR-34a, as a tumor suppressor, has been reported to serve a key role in several types of solid tumors, including renal cell carcinoma (77), glioblastoma (78) and colon cancer (79). The expression of miR-34a was downregulated by $36 \%$ in CRC tissues compared with healthy tissues (80). In addition, Zhang et al (79) and $\mathrm{Wu}$ et al (57) suggested that miR-34a suppressed CRC metastasis and invasion. Together, the aforementioned studies suggest that miR-34a serves a key role in CRC. However, whether melatonin exerts its antitumor effects by regulating the expression of the miR-34a/449a cluster has not been previously reported, therefore, whether this cluster was involved in the therapeutic effects of melatonin was assessed in the present study. Compared with the control group, melatonin significantly increased the expression of the miR-34a/449a cluster. Furthermore, melatonin inhibited proliferation and viability, and induced apoptosis in CRC cells via upregulating the expression of the miR-34a/449a cluster. To the best of our knowledge, the present study was the first to suggest the important regulatory function of miRNAs in melatonin-induced antiproliferative and proapoptotic activities of CRC cells, providing further evidence to support the critical role of miRNAs in melatonin-treated cancer.

In the present study, the bioinformatics based target prediction suggested that Notch1 and Bcl-2 were direct target genes of the miR-34a/449a cluster. Notch1 and Bcl-2 are critical regulators of CRC cell proliferation, apoptosis and development (81-83). Notch1 and Bcl-2 are regulated by miRNAs in various types of cancer. In gastric cancer, miR-708 targeted Notch1 and subsequently suppressed cell proliferation (84). In CRC cells, miR-34a directly targeted Notch1, which was associated with tumor invasion and metastasis (79). In renal cell carcinoma, miR-34a inhibited cell proliferation by targeting Notch1 (77). Thus, whether melatonin-mediated upregulation of the miR-34a/449a cluster, resulting in downregulation of Notch1, ultimately inhibited CRC cell proliferation was assessed. In human cervical cancer, Bcl-2 is the target of miR-34a-5p and is associated with proliferation and apoptosis (85). In prostate carcinoma, miR-205 and miR-338-3p downregulate the expression of the Bcl-2, which ultimately results in decreased apoptosis (72). Numerous studies have demonstrated that Bcl-2 is regulated by various miRNAs, which subsequently affects cell apoptosis $(37,38)$. However, the relationship among melatonin, the miR-34a/449a cluster and Bcl-2 in CRC is not completely understood. It was hypothesized that melatonin upregulated the miR-34a/449a cluster by downregulating Bcl-2 expression, which subsequently induced CRC cell apoptosis. The results indicated that melatonin upregulated the expression of the miR-34a/449a cluster, which resulted in downregulated Notch1 and $\mathrm{Bcl}-2$ expression levels compared with the control group. The results indicated that the miR-34a/449a/Notch1/Bcl-2 axis may serve as a critical mediator of melatonin-treated CRC.

In summary, the present study demonstrated that melatonin inhibited proliferation and viability, and induced apoptosis of CRC cells via upregulating the expression of the miR-34a/449a cluster (Fig. 6). To the best of our knowledge, the present study was the first to identify an association among melatonin, the miR-34a/449a cluster, Notch1 and Bcl-2 in CRC. The results suggested that melatonin may be useful as a single or adjuvant therapeutic for CRC.

\section{Acknowledgements}

Not applicable.

\section{Funding}

The present study was supported by the Natural Science Foundation of Shandong Province (grant no. 2018GSF118076).

\section{Availability of data and materials}

The datasets used and/or analyzed during the current study are available from the corresponding author on reasonable request.

\section{Authors' contributions}

GJ and HH designed the experiments. GJ, JD, XiaL, HH and XinL acquired and analysed data for the work. GJ, WZ and XiaL revised the manuscript for important intellectual content. WZ was involved in acquiring and analyzing data for the work, and designing the in vivo experiments. HH gave final approval of the version to be published. GJ and $\mathrm{HH}$ agreed to be accountable for the work in ensuring that questions related to the integrity of any part of the work are appropriately investigated and resolved. All authors read and approved the final manuscript.

\section{Ethics approval and consent to participate}

The present study followed the Guide for the Care and Use of Laboratory Animals (Eighth edition; 2011) in Animal Care and Treatment. The present study was approved by the Ethics Committee on Animal Experiments of the Medical School of Shandong University (approval no. KYLL-2017(KS)-357).

\section{Patient consent for publication}

Not applicable.

\section{Competing interests}

The authors declare that they have no competing interests.

\section{References}

1. Chen W, Zheng R, Baade PD, Zhang S, Zeng H, Bray F, Jemal A, Yu XQ and He J: Cancer statistics in China, 2015. CA Cancer J Clin 66: 115-132, 2016.

2. Siegel RLM, Miller KD and Jemal A: Cancer statistics, 2020. CA Cancer J Clin 70: 7-30, 2020.

3. Zhang Y, Chen Z and Li J: The current status of treatment for colorectal cancer in China: A systematic review. Medicine (Baltimore) 96: e8242, 2017.

4. Scholefield JH and Steele RJ; British Society For Gastroenterology; Association of Coloproctology for Great Britain and Ireland: Guidelines for follow up after resection of colorectal cancer. Gut 51 (Suppl 5): V3-V5, 2002.

5. Cunningham D, Humblet Y, Siena S, Khayat D, Bleiberg H, Santoro A, Bets D, Mueser M, Harstrick A, Verslype C, et al: Cetuximab monotherapy and cetuximab plus irinotecan in irinotecan-refractory metastatic colorectal cancer. N Engl J Med 351: 337-345, 2004. 
6. Van Cutsem E, Peeters M, Siena S, Humblet Y, Hendlisz A, Neyns B, Canon JL, Van Laethem JL, Maurel J, Richardson G, et al: Open-label phase III trial of panitumumab plus best supportive care compared with best supportive care alone in patients with chemotherapy-refractory metastatic colorectal cancer. J Clin Oncol 25: 1658-1664, 2007.

7. Wu H, Liu J, Yin Y, Zhang D, Xia P and Zhu G: Therapeutic opportunities in colorectal cancer: Focus on melatonin antioncogenic action. BioMed Res Int 2019: 9740568, 2019.

8. Claustrat B, Brun J and Chazot G: The basic physiology and pathophysiology of melatonin. Sleep Med Rev 9: 11-24, 2005.

9. Acuña-Castroviejo D, Escames G, Venegas C, Díaz-Casado ME Lima-Cabello E, López LC, Rosales-Corral S, Tan DX and Reiter RJ: Extrapineal melatonin: Sources, regulation, and potential functions. Cell Mol Life Sci 71: 2997-3025, 2014.

10. Bubenik GA: Gastrointestinal melatonin: Localization, function, and clinical relevance. Dig Dis Sci 47: 2336-2348, 2002.

11. Reiter RJ; RJ R: Melatonin: The chemical expression of darkness. Mol Cell Endocrinol 79: C153-C158, 1991.

12. Reiter RJ, Tan DX, Mayo JC, Sainz RM, Leon J and Czarnocki Z Melatonin as an antioxidant: biochemical mechanisms and pathophysiological implications in humans. Acta Biochim Pol 50: 1129-1146, 2003.

13. Min KJ, Jang JH and Kwon TK: Inhibitory effects of melatonin on the lipopolysaccharide-induced $\mathrm{CC}$ chemokine expression in BV2 murine microglial cells are mediated by suppression of Akt-induced NF- $\kappa$ B and STAT/GAS activity. J Pineal Res 52: 296-304, 2012

14. Joo SS and Yoo YM: Melatonin induces apoptotic death in LNCaP cells via p38 and JNK pathways: Therapeutic implications for prostate cancer. J Pineal Res 47: 8-14, 2009.

15. Zha L, Fan L, Sun G, Wang H, Ma T, Zhong F and Wei W: Melatonin sensitizes human hepatoma cells to endoplasmic reticulum stress-induced apoptosis. J Pineal Res 52: 322-331, 2012

16. Ren W, Wang P, Yan J, Liu G, Zeng B, Hussain T, Peng C, Yin J, $\mathrm{Li} \mathrm{T}$, Wei $\mathrm{H}$, et al: Melatonin alleviates weanling stress in mice: Involvement of intestinal microbiota. J Pineal Res: Dec 20, 2017 (Epub ahead of print). doi: 10.1111/jpi.12448.

17. Yin J, Li Y, Han H, Chen S, Gao J, Liu G, Wu X, Deng J, Yu Q, Huang X, et al: Melatonin reprogramming of gut microbiota improves lipid dysmetabolism in high-fat diet-fed mice. J Pineal Res 65: e12524, 2018.

18. Kannen V, Marini T, Zanette DL, Frajacomo FT, Silva GE Jr, Silva WA Jr and Garcia SB: The melatonin action on stromal stem cells within pericryptal area in colon cancer model under constant light. Biochem Biophys Res Commun 405: 593-598, 2011.

19. Wang J, Guo W, Chen W, Yu W, Tian Y, Fu L, Shi D, Tong B, Xiao X, Huang W, et al: Melatonin potentiates the antiproliferative and pro-apoptotic effects of ursolic acid in colon cancer cells by modulating multiple signaling pathways. J Pineal Res 54 406-416, 2013

20. Anisimov VN: Light pollution, reproductive function and cancer risk. Neuro Endocrinol Lett 27: 35-52, 2006.

21. Anisimov VN, Vinogradova IA, Panchenko AV, Popovich IG and Zabezhinski MA: Light-at-night-induced circadian disruption, cancer and aging. Curr Aging Sci 5: 170-177, 2012.

22. Riabykh TP, Nikolaeva TG and Bodrova NB: Effects of biorhythm regulator melatonin on DNA synthesis in short-term cultures of human malignant tumors. Vestn Ross Akad Med Nauk 8: 30-33, 2000 (In Russian).

23. Farriol M, Venereo Y, Orta X, Castellanos JM and SegoviaSilvestre T: In vitro effects of melatonin on cell proliferation in a colon adenocarcinoma line. J Appl Toxicol 20: 21-24, 2000.

24. Anisimov VN, Popovich IG and Zabezhinski MA: Melatonin and colon carcinogenesis: I. Inhibitory effect of melatonin on development of intestinal tumors induced by 1,2-dimethylhydrazine in rats. Carcinogenesis 18: 1549-1553,1997.

25. Hong Y, Won J, Lee Y, Lee S, Park K, Chang KT and Hong Y: Melatonin treatment induces interplay of apoptosis, autophagy, and senescence in human colorectal cancer cells. J Pineal Res 56: 264-274, 2014

26. León J, Casado J, Sergio M, Ruiz J, Zurita MS, González-Puga C, Rejón JD, Gila A, Muñoz de Rueda P, Pavón EJ, et al: Melatonin reduces endothelin-1 expression and secretion in colon cancer cells through the inactivation of FoxO-1 and NF-kappaß. J Pineal Res 56: 415-426, 2014.

27. Yu X, Zheng H, Chan MT and Wu WK: Modulation of chemoresponsiveness to platinum-based agents by microRNAs in cancer. Am J Cancer Res 7: 1769-1778, 2017.
28. Dacosta C and Bao Y: The role of MicroRNAs in the chemopreventive activity of sulforaphane from cruciferous vegetables. Nutrients 9: 902, 2017.

29. Cochetti G, Rossi de Vermandois JA, Maulà V, Giulietti M, Cecati M, Del Zingaro M, Cagnani R, Suvieri C, Paladini A and Mearini E: Role of miRNAs in prostate cancer: Do we really know everything? Urol Oncol 38: 623-635, 2020.

30. Shibuya $H$, Iinuma $H$, Shimada $R$, Horiuchi $A$ and Watanabe $T$ : Clinicopathological and prognostic value of microRNA-21 and microRNA-155 in colorectal cancer. Oncology 79: 313-320, 2010

31. Liu L, Chen L, Xu Y, Li R and Du X: microRNA-195 promotes apoptosis and suppresses tumorigenicity of human colorectal cancer cells. Biochem Biophys Res Commun 400: 236-240, 2010.

32. Lu TX and Rothenberg ME: MicroRNA. J Allergy Clin Immunol 141: 1202-1207, 2018.

33. Wong TS, Man OY, Tsang CM, Tsao SW, Tsang RK, Chan JY, Ho WK, Wei WI and To VS: MicroRNA let-7 suppresses nasopharyngeal carcinoma cells proliferation through downregulating c-Myc expression. J Cancer Res Clin Oncol 137 415-422, 2011.

34. Kang L, Mao J, Tao Y, Song B, Ma W, Lu Y, Zhao L, Li J, Yang B and Li L: MicroRNA-34a suppresses the breast cancer stem cell-like characteristics by downregulating Notch1 pathway. Cancer Sci 106: 700-708, 2015.

35. Godlewski J, Nowicki MO, Bronisz A, Williams S, Otsuki A, Nuovo G, Raychaudhury A, Newton HB, Chiocca EA and Lawler S: Targeting of the Bmi-1 oncogene/stem cell renewal factor by microRNA-128 inhibits glioma proliferation and self-renewal. Cancer Res 68: 9125-9130, 2008.

36. Wang YB, Zhao XH, Li G, Zheng JH and Qiu W: MicroRNA-184 inhibits proliferation and promotes apoptosis of human colon cancer SW480 and HCT116 cells by downregulating C-MYC and BCL-2. J Cell Biochem 119: 1702-1715, 2018.

37. Li M, Yang Y, Kuang Y, Gan X, Zeng W, Liu Y and Guan H: miR-365 induces hepatocellular carcinoma cell apoptosis through targeting Bcl-2. Exp Ther Med 13: 2279-2285, 2017.

38. Tong Z, Liu N, Lin L, Guo X, Yang D and Zhang Q: miR-125a-5p inhibits cell proliferation and induces apoptosis in colon cancer via targeting BCL2, BCL2L12 and MCL1. Biomed Pharmacother 75: 129-136, 2015.

39. Rodriguez A, Griffiths-Jones S, Ashurst JL and Bradley A: Identification of mammalian microRNA host genes and transcription units. Genome Res 14: 1902-1910, 2004.

40. Tang H, Bian Y, Tu C, Wang Z, Yu Z, Liu Q, Xu G, Wu M and Li G: The miR-183/96/182 cluster regulates oxidative apoptosis and sensitizes cells to chemotherapy in gliomas. Curr Cancer Drug Targets 13: 221-231, 2013

41. Altuvia Y, Landgraf P, Lithwick G, Elefant N, Pfeffer S, Aravin A, Brownstein MJ, Tuschl T and Margalit H: Clustering and conservation patterns of human microRNAs. Nucleic Acids Res 33: 2697-2706, 2005.

42. Weber MJ: New human and mouse microRNA genes found by homology search. FEBS J 272: 59-73, 2005.

43. Zhu C, Huang Q and Zhu H: Melatonin inhibits the proliferation of gastric cancer cells through Regulating the miR-16-5p-Smad3 pathway. DNA Cell Biol 37: 244-252, 2018.

44. Sohn EJ, Won G, Lee J, Lee S and Kim SH: Upregulation of miRNA3195 and miRNA374b mediates the anti-angiogenic properties of melatonin in hypoxic PC-3 prostate cancer cells. J Cancer 6: 19-28, 2015.

45. Gu J, Lu Z, Ji C, Chen Y, Liu Y, Lei Z, Wang L, Zhang HT and $\mathrm{Li} \mathrm{X}$ : Melatonin inhibits proliferation and invasion via repression of miRNA-155 in glioma cells. Biomed Pharmacother 93: 969-975, 2017.

46. Messner M, Huether G, Lorf T, Ramadori G and Schwörer $\mathrm{H}$ : Presence of melatonin in the human hepatobiliary-gastrointestinal tract. Life Sci 69: 543-551, 2001.

47. Claustrat B and Leston J: Melatonin: Physiological effects in humans. Neurochirurgie 61: 77-84, 2015.

48. Hong Y, Won J, Lee Y, Lee S, Park K, Chang KT and Hong Y: Melatonin treatment induces interplay of apoptosis, autophagy, and senescence in human colorectal cancer cells. J Pineal Res 56 : 264-274, 2014

49. Park SY, Jang WJ, Yi EY, Jang JY, Jung Y, Jeong JW and Kim YJ: Melatonin suppresses tumor angiogenesis by inhibiting HIF-1a stabilization under hypoxia. J Pineal Res 48: 178-184, 2010.

50. Xu M, Chen X, Lin K, Zeng K, Liu X, Pan B, Xu X, Xu T, $\mathrm{Hu} X$, Sun L, et al: The long noncoding RNA SNHG1 regulates colorectal cancer cell growth through interactions with EZH2 and miR-154-5p. Mol Cancer 17: 141, 2018 
51. Zhao SJ, Shen YF, Li Q, He YJ, Zhang YK, Hu LP, Jiang YQ, Xu NW, Wang YJ, Li J, et al: SLIT2/ROBO1 axis contributes to the Warburg effect in osteosarcoma through activation of SRC/ERK/c-MYC/PFKFB2 pathway. Cell Death Dis 9: 390, 2018.

52. Livak KJS and Schmittgen TD: Analysis of relative gene expression data using real-time quantitative PCR and the 2(-Delta Delta C(T)) method. Methods 25: 402-408, 2001.

53. Yang CY, Lin CK, Tsao CH, Hsieh CC, Lin GJ, Ma KH, Shieh YS, Sytwu HK and Chen YW: Melatonin exerts anti-oral cancer effect via suppressing LSD1 in patient-derived tumor xenograft models. Oncotarget 8: 33756-33769, 2017.

54. Wang Q, Sun Z, Du L, Xu C, Wang Y, Yang B, He N, Wang J, Ji K, Liu Y, et al: Melatonin sensitizes human colorectal cancer cells to $\gamma$-ray ionizing radiation in vitro and in vivo. Int $\mathrm{J}$ Mol Sci 19: 3974, 2018

55. Marques JH, Mota AL, Oliveira JG, Lacerda JZ, Stefani JP, Ferreira LC, Castro TB, Aristizábal-Pachón AF and Zuccari DA Melatonin restrains angiogenic factors in triple-negative breast cancer by targeting miR-152-3p: In vivo and in vitro studies. Life Sci 208: 131-138, 2018.

56. Hong YG, Xin C, Zheng H, Huang ZP, Yang Y, Zhou JD, Gao XH, Hao L, Liu QZ, Zhang W, et al: miR-365a-3p regulates ADAM10-JAK-STAT signaling to suppress the growth and metastasis of colorectal cancer cells. J Cancer 11: 3634-3644, 2020

57. Wu J, Wu G, Lv L, Ren YF, Zhang XJ, Xue YF, Li G, Lu X, Sun Z and Tang KF: MicroRNA-34a inhibits migration and invasion of colon cancer cells via targeting to Fra-1. Carcinogenesis 33 519-528, 2012

58. Cekaite P, Eide PW, Lind GE, Skotheim RI and Lothe RA MicroRNAs as growth regulators, their function and biomarker status in colorectal cancer. Oncotarget 7: 6476-6505, 2015.

59. Lv J, Zhang Z, Pan L and Zhang Y: MicroRNA-34/449 family and viral infections. Virus Res 260: 1-6, 2019.

60. Sørensen NM, Schrohl AS, Jensen V, Christensen IJ, Nielsen HJ and Brünner N: Comparative studies of tissue inhibitor of metalloproteinases- 1 in plasma, serum and tumour tissue extracts from patients with primary colorectal cancer. Scand J Gastroenterol 43: 186-191, 2008.

61. Schwartz RN: Management of early and advanced colorectal cancer: Therapeutic issues. Am J Health Syst Pharm 65 (Suppl 4): S8-S14, quiz S22-S24, 2008

62. Half E and Arber N: Colon cancer: Preventive agents and the present status of chemoprevention. Expert Opin Pharmacother 10: 211-219, 2009

63. Cipolla-Neto J and Amaral FGD: Melatonin as a hormone: New physiological and clinical insights. Endocr Rev 39: 990-1028, 2018

64. Chitimus DM, Popescu MR, Voiculescu SE, Panaitescu AM Pavel B, Zagrean L and Zagrean AM: Melatonin's impact on antioxidative and anti-inflammatory reprogramming in homeostasis and disease. Biomolecules 10: 1211, 2020.

65. Zhang S, Qi Y, Zhang H, He W, Zhou Q, Gui S and Wang Y: Melatonin inhibits cell growth and migration, but promotes apoptosis in gastric cancer cell line, SGC7901. Biotech Histochem 88: 281-289, 2013.

66. Li Y, Li S, Zhou Y, Meng X,Zhang JJ, Xu DP and Li HB: Melatonin for the prevention and treatment of cancer. Oncotarget 8: 39896-39921, 2017.

67. Batista AP, da Silva TG, Teixeira AA, de Medeiros PL, Teixeira VW, Alves LC, Dos Santos FA and Silva EC: Ultrastructural aspects of melatonin cytotoxicity on Caco-2 cells in vitro. Micron 59: 17-23, 2014.

68. León J, Casado J, Jiménez Ruiz SM, Zurita MS, González-Puga C, Rejón JD, Gila A, Muñoz de Rueda P, Pavón EJ, Reiter RJ, et al: Melatonin reduces endothelin-1 expression and secretion in colon cancer cells through the inactivation of FoxO- 1 and NF- $\kappa \beta$ J Pineal Res 56: 415-426, 2014.
69. Liu Z,Zou D, Yang X, Xue X, Zuo L, Zhou Q, Hu R and Wang Y: Melatonin inhibits colon cancer RKO cell migration by downregulating Rho associated protein kinase expression via the p38/MAPK signaling pathway. Mol Med Rep 16: 9383-9392, 2017.

70. Wei JY, Li WM, Zhou LL, Lu QN and He W: Melatonin induces apoptosis of colorectal cancer cells through HDAC4 nuclear import mediated by CaMKII inactivation. J Pineal Res 58: 429-438, 2015

71. Trivedi PP, Jena GB, Tikoo KB and Kumar V: Melatonin modulated autophagy and Nrf2 signaling pathways in mice with colitis-associated colon carcinogenesis. Mol Carcinog 55: 255-267, 2016.

72. Zhang X, Pan Y, Fu H and Zhang J: microRNA-205 and microRNA-338-3p reduces cell apoptosis in prostate carcinoma tissue and $\mathrm{LNCaP}$ prostate carcinoma cells by directly targeting the B-cell lymphoma-2 (Bcl-2) gene. Med Sci Monit 25: 1122-1132, 2019.

73. Hongdan L and Feng L: miR-3120-5p promotes colon cancer stem cell stemness and invasiveness through targeting Axin2. Biochem Biophys Res Commun 496: 302-308, 2018.

74. Kim TH and Cho SG: Melatonin-induced KiSS1 expression inhibits triple-negative breast cancer cell invasiveness. Oncol Lett 14: 2511-2516, 2017.

75. Farooqi AA, Tabassum S and Ahmad A: MicroRNA-34a: A versatile regulator of myriads of targets in different cancers. Int J Mol Sci 18: 208, 2017.

76. Li XJ, Ren ZJ and Tang JH: MicroRNA-34a: A potential therapeutic target in human cancer. Cell Death Dis 5: e1327, 2014.

77. Zhang C, Mo R, Yin B, Zhou L, Liu Y and Fan J: Tumor suppressor microRNA-34a inhibits cell proliferation by targeting Notch1 in renal cell carcinoma. Oncol Lett 7: 1689-1694, 2014.

78. Yu X, Zhang W, Ning Q and Luo X: MicroRNA-34a inhibits human brain glioma cell growth by down-regulation of Notch1. J Huazhong Univ Sci Technolog Med Sci 32: 370-374, 2012.

79. Zhang X, Ai F, Li X, Tian L, Wang X, Shen S and Liu F: MicroRNA-34a suppresses colorectal cancer metastasis by regulating Notch signaling. Oncol Lett 14: 2325-2333, 2017.

80. Tazawa $H$, Tsuchiya $N$, Izumiya $M$ and Nakagama $H$ : Tumor-suppressive miR-34a induces senescence-like growth arrest through modulation of the E2F pathway in human colon cancer cells. Proc Natl Acad Sci USA 104: 15472-15477, 2007.

81. Lindner AU, Salvucci M, Morgan C, Monsefi N, Resler AJ, Cremona M, Curry S, Toomey S, O'Byrne R, Bacon O, et al: BCL-2 system analysis identifies high-risk colorectal cancer patients. Gut 66: 2141-2148, 2017

82. Ishiguro H, Okubo T, Kuwabara Y, Kimura M, Mitsui A, Sugito N, Ogawa R, Katada T, Tanaka T, Shiozaki M, et al: NOTCH1 activates the Wnt/ $\beta$-catenin signaling pathway in colon cancer. Oncotarget 8: 60378-60389, 2017.

83. Ramesh P and Medema JP: BCL-2 family deregulation in colorectal cancer: Potential for BH3 mimetics in therapy. Apoptosis 25: 305-320, 2020.

84. Li X,Zhong X, Pan X and Ji Y: Tumor suppressive microRNA-708 targets Notch1 to suppress cell proliferation and invasion in gastric cancer. Oncol Res 26: 1317-1326, 2018

85. Wang X, Xie Y and Wang J: [ARTICLE WITHDRAWN] Overexpression of microRNA-34a-5p inhibits proliferation and promotes apoptosis of human cervical cancer cells by downregulation of Bcl-2. Oncol Res 26: 977-985, 2018.

This work is licensed under a Creative Commons Attribution-NonCommercial-NoDerivatives 4.0 International (CC BY-NC-ND 4.0) License. 